\title{
Cover-seeking behavior and ecdysis in red-spitting cobras (Naja pallida)
}

\author{
DAVID CHISZAR and HOBART M. SMITH \\ Univerity of Colorado, Boulder, Colorado \\ CHARLES W. RADCLIFFE \\ San Diego Zoo, San Diego, California \\ and \\ JOHN L. BEHLER \\ New York Zoological Society, Bronx, New York
}

\begin{abstract}
During a study of cover-seeking behavior in red-spitting cobras (Naja pallida, $N=11$ ), all but one of the snakes shed. We conducted a post hoc analysis that examined changes in cover-seeking prior to and after shedding, with the result that significant increases in cover-seeking were seen as early as 8 days prior to ecdysis. This corresponds to the time at which the earliest morphological signs of impending ecdysis make their appearance but is well before the time when visual and lingual sensory disruptions should be maximal. Accordingly, we suggest that cover-seeking is not elicited by the sensory disruptions of ecdysis, but that it anticipates them.
\end{abstract}

The histological events associated with ecdysis in snakes have been studied extensively (Bechtel, 1957; Forks, 1983; Maderson, 1964, 1965, 1986), and at least one report has examined the chronology of the process, demonstrating that visible signs of impending ecdysis begin to appear between 8 and 10 days prior to skin sloughing in Vipera ammodytes, and $V$. berus (Környei, 1982). Snakes commonly seek cover during the presloughing period, and we wondered if the drive to seek cover would manifest itself as early in the process of ecdysis as the earliest external morphological signs reported by Környei (1982). The data described below indicate that this is indeed the case.

\section{METHOD}

Subjects were 11 red-spitting cobras (Naja pallida $=N$. mossambica pallida) on loan to the University of Colorado by the New York Zoological Society. The snakes were housed individually in glass terraria $(50 \times 27.5 \times 30 \mathrm{~cm})$, each containing paper floor covers, a glass bowl filled with water, and a Plexiglas hiding box $(10 \times 10 \times 2.5 \mathrm{~cm})$. Three slightly different types of hiding boxes (differing in degree of opacity) were used in successive replications of this study, but the results were always the same (see Chiszar, Radcliffe, Boyer, \& Behler, 1987; Radcliffe $\&$ Chiszar, 1983). Hence, we are confident that the findings are reasonably general, and the data will be pooled across replications for presentation here.

The authors thank Thomas Boyer, Karen Estep, and Kathryn Stimac for their help in gathering data. They also thank James Geidel for making the hiding boxes. H. M. Smith is in the Department of E.P.O. Biology at the University of Colorado, C. W. Radcliffe is in the Department of Herpetology at the San Diego Zoo, and J. L. Behler is in the Department of Herpetology, New York Zoological Society. Correspondence should be addressed to D. Chiszar, Department of Psychology, Campus Box 345, University of Colorado, Boulder, CO 80309.
Each replication used the following procedure. Observers visited the laboratory four to six times per day, and during each visit they recorded on checksheets whether or not each snake was in its hiding box. At least 30 min separated successive observations. A snake was scored as "in hiding box" if its head was inside, regardless of how much of its body was outside. However, in the vast majority of cases, when a snake's head was in the hiding box the rest of its body was also inside. Each replication continued for 21 days, and each snake was scored an average of 115 times per replication. The snakes were fed once per replication (one mouse, Mus musculus, $20 \mathrm{~g}$ ). Furthermore, 10 of the snakes shed during the three replications. Consequently, for these 10 animals we could conduct a post hoc analysis by identifying the day of ecdysis and then averaging scores over snakes as a function of days prior to and following the day of ecdysis.

\section{RESULTS AND DISCUSSION}

Red-spitting cobras not nearing ecdysis were in hiding boxes an average of $55.7 \%$ of the time. Immediately after feeding, this figure rose to $87.6 \%$, dropping again to $55.7 \%$ or less within 2 weeks (see Chiszar et al., 1987, for a detailed presentation of these data). Impending ecdysis, however, was characterized by scores of nearly $100 \%$. This was especially clear during the 4 days preceding ecdysis (Table 1). Higher than baseline use of hiding boxes was seen as early as $\mathbf{8}$ days prior to ecdysis. Return to baseline was seen on the first 2-day block following ecdysis.

The data summarized in Table 1 were subjected to a repeated measures analysis of variance (ANOVA), which confirmed the significance of the variation in mean hidingbox scores over blocks $[F(7,63)=11.06, p<.01]$. Tests after the ANOVA (Duncan's new multiple range test) showed that means did not differ on Blocks $0,-1,-2$, and -3 . Most of these means were significantly higher 
Table 1

Mean Percent of Observations Scored as "In Hiding Box," as a Function of 2-Day Blocks Preceding and Following the Day of Ecdysis (Day 0)

\begin{tabular}{cccccccc}
\hline Baseline & -5 & -4 & -3 & -2 & -1 & 0 & +1 \\
\hline $55.7^{\mathrm{a}}$ & $52.2^{\mathrm{a}}$ & $74.0^{\mathrm{b}}$ & $81.0^{\mathrm{b}, \mathrm{c}}$ & $95.6^{\mathrm{c}}$ & $93.4^{\mathrm{c}}$ & $86.7^{\mathrm{c}}$ & $43.2^{\mathrm{a}}$
\end{tabular}

Note-Means with the same superscript do not differ significantly by Duncan's new multiple-range test (.05 level). *Span of time during which eyes are opaque.

than the means on Blocks -4 and +1 . Importantly, the mean on Block -4 was significantly higher than that on Block +1 and the baseline value of 55.7\% .

This pattern of results agrees closely with the anatomical data reported by Környei (1982). Assuming that the viperid processes studied by Környei also occur in elapids, it appears that cover-seeking drive increases precisely when the earliest external anatomical signs of ecdysis become manifest. Only two explanations seem capable of embracing this correlation. Either cover-seeking behavior is triggered by the earliest signs of ecdysis or both of these factors are controlled by the physiological processes that precede and determine the early signs. Deciding between these positions is not possible on the basis of present data, but the second hypothesis seems most likely. For example, ecdysis gives rise to increased cutaneous water loss, and cover-seeking in nature almost certainly would put snakes in favorable, humid microhabitats (Benedict, 1932; Bogert \& Cowles, 1947; Graves, Duvall, King, Lindstedt, \& Gern, 1986). Hence, ecdysis-induced cover-seeking may be as much related to hydration needs as to selfdefense. However this matter turns out, it is clear that cover-seeking increases well before the eyes become opaque. Hence, cover-seeking is probably not triggered by visual disruption but, rather, anticipates it. Likewise, we infer that cover-seeking also anticipates lingual (and presumably vomeronasal) disruption occasioned by the sloughing of the skin from the tips of the tongue.

\section{REFERENCES}

BeCHTEL, H. B. (1957). Some microscopic aspects of ecdysis in snakes. Herpetologica, 13, 177-181.

BENEDICT, F. B. (1932). The physiology of large reptiles with special reference to the heat production of snakes, tortoises, lizards, and alligators (Publication 425, pp. 1-539). Washington, DC: Carnegie Institution.

BoGerT, C. M., * Cowles, R. B. (1947). Moisture loss in relation to habitat selection in some Floridian reptiles. American Museum Novitates, No. 1358, 1-34.

Chiszar, D., Radcuffe, C. W., Boyer, T., \& Behler, J. L. (1987). Cover-seeking behavior in red spitting cobras (Naja mossambica pallida): Effects of tactile cues and darkness. Zoo Biology, 6, 161-167.

Forks, T. P. (1983). The histology of ecdysis in snakes. Bulletin of the Chicago Herpetological Society, 18, 1-6.

Graves, B. M., Duvall, D., King, M. B., Lindstedt, S. L., \& Gern, W. A. (1986). Initial den location by neonatal prairie rattlesnakes: Functions, causes and natural history in chemical ecology. In D. Duvall, D. Müller-Schwarze, \& R. M. Silverstein (Eds.), Chemical signals in vertebrates 4 (pp. 285-304). New York: Plenum.

KöRNYEI, T. M. (1982). Observations in Vipera ammodytes and Vipera berus during the pre-sloughing period. Bulletin of the Chicago Herpetological Society, 17, 85-95.

Maderson, P. F. A. (1964). The skin of lizards and snakes. British Journal of Herpetology, 3, 151-154.

MAdERSON, P. F. A. (1965). Histological changes in the epidermis of snakes during the sloughing cycle. Journal of Zoology, 146, 98-113.

Maderson, P. F. A. (1986). The tetrapod epidermis: A system protoadapted as a semiochemical source. In D. Duvall, D. MüllerSchwarze, \& R. M. Silverstein (Eds.), Chemical signals in vertebrates 4 (pp. 13-25). New York: Plenum.

Radcliffe, C. W., \& Chiszar, D. (1983). Clear plastic hiding boxes as a husbandry device for nervous snakes. Herpetological Review, $14,18$.

(Manuscript received December 2, 1991.) 